\title{
How Can Role-Plays Increase Speaking Participation For The Working Adult Students? : Action Research
}

\author{
Thi K.T Nguyen \\ School of Foreign Languages - Cantho University, Vietnam
}

\begin{abstract}
Not participating in speaking activities is a common problems in the English as a Foreign Language bachelor classes of the second degree of Cantho University, Vietnam, but according to Ur (1996) speaking seems to be the most important skills of all the four skills. Many of the students are middle-aged ones that are used to Grammar translation method in their past study. To solve this problem, I used 'role-plays' to create many situations for them to speak out. Twenty four students of the 16th Language Kiengiang course trained by Cantho University were selected. They were in the first semester of the first year with the subject, Communication 1, and almost all of them were at pre-intermediate level of listening and speaking skill. Most of them were in their 30s and 40s, and five of them were in their 20s and three in their 50s. Ten sessions were treated with ten types of activities of role-plays done in pairs, small groups, big groups and the whole class. With daily observation, interviews, a questionnaire the result was that ten role-plays helped the working adult students in their 20s-50s to participate in speaking English significantly. Although it was difficult for the 50s, they could fulfil their talk in a basic and short answers with the help of the teacher. The role-plays in pairs and small groups helped the weak students than the big group but the tasks of big group were more effective for good students. Therefore, I suggest that role-plays should be used in the working adult students.
\end{abstract}

Keywords: EFL, role-plays, speaking activities, speaking ability.

\section{Introduction}

Poor speaking participation is the common issue in 16th EFL Language Kiengiang course - an EFL bachelor class of the second degree of Cantho University. Most of these worker students were in their 30s and 40 s, and almost all of them were the teachers of Kiengiang vocational college - some were white collar shirt workers in Kiengiang. They went to this class because they tried to demand the criteria of the government in pay and worker ranks, wanted to communicate in English in some training courses of their majors in South East Asian and in the future they will teach their majors in English. After tiring working hours, the worker students went to their English class with many life worries. They were also unequal in English competence, were good at skills unequally, and many of them were used to Grammar translation teaching method they learned in the past. In their age it is slow to learn new things especially those they are not majored in as Harmer (1989) said, "Adults worry that their intellectual power may be diminishing with age.' Therefore, how to help as many students as possible sit down in the class and take part in the speaking activities is my concern. Thinking of my case of learning French, I found some reasons for myself and I decided to choose role-plays to help them speak more because there are many benefits such as interesting, safe speaking environment, good communication.

\section{Questions}

The questions are:

1. Can role-plays attract the students in their 20s-50s participate in speaking?

2. Can role-plays strengthen the weak students in their 20s-50s to speak?

The importance of speaking

\section{Background}

Speaking seems to be the most important skills of all the four skills (listening, speaking, reading and writing) because people who know a language are usually referred to as speakers of that language (Ur, 1996).

\section{The reasons for not participating in speaking activities}

Linguistic and listening skill barriers

We need linguistic competence, an adequate vocabulary and mastery of syntax to speak in another language (Nunan, 1999). Also, in the Common European Framework (2001), linguistic competence is one of three communicative competence. The students can't speak out if they do not have enough support from the teacher with the basic linguistic competence. To listening skill, Doff (1998) stated speaking skills couldn't be developed unless we developed listening skills. 


\section{Lack of topical knowledge}

Bachman \& Palmer (1996) believed that topical knowledge had effects on speaking performance. They stated a certain test tasks might be easier for those who possessed the relevant topical knowledge and more difficult for those who did not. Rivers (1968) also believed that the learners had nothing to express maybe because the teacher chose a topic which was not suitable for him or about which he knew very little.

\section{Boring activities}

In http://www.teachingenglish.org.uk/article/teaching-speaking-skills-2-overcoming-classroomproblems, a completely different reason for student silence may simply be that the class activities are boring, let's take a closer look at the type of speaking activities the teacher is using and see if students are interest in them and they create a real need for communication.

\section{Self-confidence and shyness}

A variety of affective variables has been confirmed to be related to success in second language acquisition in research over the last decade but self-confidence is one of the studies examined (Krashen, 1982). In some cultures it is unusual for students to talk out loud in class, and students feel really shy about talking in front of other students (http://www.teachingenglish.org.uk/article/teaching-speaking-skills-2-overcomingclassroom-problems).

\section{Students who Participate too much}

Snow (2007) wrote that teachers were probably familiar with the kind of students who tended to dominate, always being the first. This group of students made others especially weak ones have fewer chances to speak out.

\section{Fear of Making Mistakes and negative evaluation}

According to Nunan (1999), Canale and Swain (1980), the Common European Framework (2001), sociolinguistic was one three components of communicative competence the speaker needs. Don (2007) stated that fear of speaking out in a foreign language - especially in front of the whole - prevented students from speaking. He added that this case was a rather common problem in many settings and cultures because it was quite natural for students to be reluctant to make mistakes in public, and simply they weren't used to it; it also tended to be more of a problem in cultures where individual display was not encouraged and where face was considered very important.

About evaluation, according to Ely (1986), students who experienced fear of negative evaluation did not consider language errors as a natural part of the learning process, but as a threat to their image, and a source for negative evaluations either from the teacher or their peers. As a result, they were silent and withdrew most of the time, and did not participate in language activities.

\section{Threatening tasks}

According to Nation (1997), learners were reluctant to speak English because they felt the task was threatening and embarrassing. As McArthur (1983) mentioned that students knew very well what they should have done, but owing to the nervousness, tiredness, pressure and the effects of inner translation, they just lapsed and forget for a moment what to do. Teachers should realize that language learning, and particularly oral production, is a potentially stressful situation for some students, and that the "tension and discomfort related to language learning is an important issue of the language teaching profession" (Horwitz, 2001).

\section{Wrong level}

http://www.teachingenglish.org.uk/article/teaching-speaking-skills-2-overcoming-classroom-problems mentions the right level for the students. Is the activity or task pitched at the right level for them? Make sure the teacher give the students all the tools and language they need to be able to complete the task. If the language is pitched too high they may revert to their L1, likewise if the task is too easy they may get bored and revert to their L1.

\section{Low motivation}

Krashen (1982) stated that a variety of affective variables had been confirmed to be related to success in second language acquisition in research over the last decade but motivation was one of the studies examined. To Snow (2007) time diminished students' interest of learning English because of its rare use. Day by day the novelty of learning a foreign language wore off, and students began to be tired of hard work that seemed to have no end in sight. There were also generally few opportunities in EFL settings for students to make genuine use of beginning- or intermediate-level English skills, so the ratio of reward to effort tended to be rather low. 
Additionally, it becomed harder for students to see what - if any-progress they were making, especially in the intermediate stages of English study when they studied low-frequency vocabulary items and grammar structures that might not appear for months or years after students first learnt them. Finally, the ultimate goal might still seem quite distant and unreal. In this phase, many students lost interest in building genuine proficiency in English - or lost hope that they would ever be able to attain such proficiency - and began to settle for the less ambitious goal of simply doing what was necessary to pass tests whether or not this actually helped them build genuine skills.

\section{Be used to using $L 1$}

Harmer (1991) suggested some reasons why students used mother tongue in class. Firstly, when the students were asked to have a discussion about a topic that they were incapable of, if they wanted to say anything about the topic, they would use their own language. Another reason was that the use of mother- tongue was a natural thing to do. In addition, using the first language to explain something to another if there was no encouragement from the teachers. Finally, if teachers frequently used the students' language, the students would feel comfortable to do it.

\section{Role-play and its effects Definition}

In http://www.teachingenglish.org.uk/article/role-play Role-play is defined as any speaking activity when you either put yourself into somebody else's shoes, or when you stay in your own shoes but put yourself into an imaginary situation! The students imagine that they become anyone for a short time such as a witness of a robbery, a fan of pop stars, the chairman of a company, etc. Imaginary situations can be a multitude of scenarios such as 'at a bank', checking in at a hotel', 'describing a robber'.

For a role-play to work, it must have the following characteristics (Jones, 1982, cited in Harmer 1989)

1. Reality of function: the students must not think of themselves as students, but as real participants in the situation

2. A simulated environment: the teacher says that the classroom is an airport check-in area for example.

3. Structure: students must see how is how constructed and they must be given the necessary information to carry out the simulation effectively

\section{Types of Role-Playing Exercises (in the study by Rajkumar (2012)}

Role-playing can be thought of as unstructured drama. In these exercises, a student looks at the topic from the perspective of a character, which will affect and be affected by the topic. The instructor provides the setting and the characters, but the students have to decide their characters' lines and directions. Generally, the students will need to do some research to make informed decisions from their characters' perspectives. This research opportunity can easily become an inquiry element. Role-playing exercises teach skills that are often assumed to be learned outside of the classroom, and how to use those skills to complement scientific knowledge. These exercises require the students to use imagination, background knowledge appropriate to the character being role-played, and communications skills.

\section{Individual Role-Playing Exercises}

Students research and present the issue being studied in a format which is appropriate to the characters they've been assigned: a report to the rector, or a description of a robber by a witness. The challenge for these exercises is for the student to "get into character", to accept and work in the role that they've been assigned, especially if their character is very different from them. For example, students could have a general lecture telephone conversation, handling business calls, phatic communion etc and thereby asking the students to do pair work by giving them imaginary situations.

\section{Interactive Role-Playing Exercises}

These are group projects that range from simple brainstorming exercises or scripted demonstrations to in-character debates, group discussions dealing with environmental or current affairs topics. These lessons may include individual assignments to prepare the students for their roles and for the project as a whole. It is easier for students to get into character and stay there with help from their classmates, but keeping the debate friendly and productive can be challenging. Some examples - Debate on "Science is a boon or a Bane", Brain Drain etc.

\section{Why use role-play to get the students involved in speaking?}

Ladousse (2004) indicated, "Role play is one of a whole gamut of communicative techniques which develops fluency in language students, which promotes interaction in the classroom, and which increases motivation." In addition, he pointed out that role play encourages peer learning and sharing the responsibility for 
learning between teacher and student. He suggested role play to be "perhaps the most flexible technique in the range" of communicative techniques, and with suitable and effective role-play exercises, teachers could meet an infinite variety of needs. Brown and Yule (1995) all stated that constructive role play could help students become more interested and involved in classroom learning by addressing problems, and exploring alternatives and creative solutions in terms of not only material learning, but also in terms of integrating the knowledge learned in action. Harmer (1989) also listed three advantages:

- $\quad$ Fun, motivating

- Allow hesitate students to be more forthright in their opinion and behavior than they might be when speaking for themselves, since they do not have to take the same responsibility for what they are saying

- $\quad$ By broadening the world of the classroom to include the world outside, they allow students to use a much wider range of language than some more tasks-center activities may do.

In http://www.teachingenglish.org.uk/article/role-play it is added some more benefits of role-play. First, students who will be at some point travel to an English-speaking country are given a chance to rehearse their English in a safe environment. Second, real situations can be created and students can benefit from the practice. Finally, mistakes can be made with no drastic consequences.

To sum up, most reasons of not joining in speaking EFL such as poor motivation, boring activities, self-confidence and shyness, threatening tasks, 'students who Participate too much', fear of mistakes, English environment are solved if role-plays are used. The rest such as linguistic and listening skill barriers, lack of topical knowledge, wrong level, 'Was the timing of the activity good?', 'be used to using L1' are going to be solved in the following part with 'How to Teach Using Role-Playing?' and 'Tips on successful classroom roleplay'.

\section{How to Teach Using Role-Playing?}

Rajkumar (2012) claimed that role-playing exercises could be hard work for the instructor, both in preparation and in action, but the work tended to pay off in terms of student motivation and accomplishment. Fortunately, much of the work of preparation, once done, could be distributed to other educators. As with any big project, it was the best to take it one step at a time: define objectives, choose context \& roles, introducing the exercise, student preparation, the role-play, concluding discussion, assessment, classroom techniques, practices and behaviors.

The role playing/simulation procedure described here uses Ladousse (1987) format applied to "The Island Game," a simulation described by Crookall and Oxford (1990b). Ladousse viewed procedure as one of 11 factors in role plays. These factors were: level, time, aim, language, organization, preparation, warm-up, procedure, follow-up, remarks and variations. Various role playing exercises were then described in terms of these factors. Level indicated the minimum (and sometimes maximum) level at which the activity could be carried out. Time might depend on whether students need to read articles, reports, etc. Aim indicated the broader objective of each activity, such as developing confidence or becoming sensitive to concepts expressed in language. Language indicated the language the students would need, such as structures, functions, different skills, work with register, or intonation patterns. Organization described whether the activity involved pair work or group work, and in the latter case, how many students should be in each group. Preparation indicated anything that needed to be done before class. Warm-up involved ideas to focus the students' attention and got them interested.

\section{Procedure}

Procedure involves a step-by-step guide to the activity. Richards (1985, cited in Rajkumar 2012), for example, recommended a six step procedure for role playing: preliminary activity, a model dialogue, learning to perform the role play with the help of role cards, listening to recordings of native speakers performing the role play with role cards, follow-up, and repeating the sequence. However, many role playing/simulation procedures did not follow these steps. Follow-up indicated activities that were done after the activity, perhaps as homework. Remarks might be of general interest or may be warnings about special difficulties that may arose. Variations could be used with different types of classes or different levels.

Tips on successful classroom role-play: presented in http://www.teachingenglish.org.uk/article/role-play Prepare for success

Role-play is possible at elementary levels providing the students have been thoroughly prepared. Try to think through the language the students will need and make sure this language has been presented. Students may need the extra support of having the language on the board. I recently did a 'lost property office' role-play with elementary adults and we spent time beforehand drilling the structures the students would need to use. When the 
role-play began the students felt 'armed' with the appropriate language. At higher levels the students will not need so much support with the language but they will need time to 'get into' the role.

The role of the teacher

Some of the possible teacher roles are:

- Facilitator - students may need new language to be 'fed' in by the teacher. If rehearsal time is appropriate the feeding in of new language should take place at this stage.

- Spectator - The teacher watches the role-play and offers comments and advice at the end.

- Participant - It is sometimes appropriate to get involved and take part in the role-play yourself.

Bring situations to life

Realia and props can really bring a role-play to life. A group of my young learners recently played the roles of pizza chef and customer. A simple cone of white card with CHEF written on it took a minute to make and I believe it made the whole process more fun and memorable for the class. As soon as it was placed on their heads they 'became' the pizza chef and acted accordingly.

Rearranging the furniture can also help. If you are imagining you are at the tourist information office or at the doctor's surgery try to make it as real as you can. Students can even leave the room and make an entrance by knocking on the door.

\section{Keep it real and relevant}

Try to keep the roles you ask students to play as real to life as possible. It may be hard for students who have little opportunity to travel to imagine they are in 'Ye Olde Tea Shop' in the heart of the English countryside. However, it may be within their schema to imagine they have been asked to help an English speaker who is visiting their own country. This may involve using some L1 to explain about the local culture or to translate local menus into English for the guest to their country.

\section{Feed-in language}

As students practice the role-play, they might find that they are stuck for words and phrases. In the practice stage the teacher has a chance to 'feed-in' the appropriate language. This may need the teacher to act as a sort of 'walking dictionary', monitoring the class and offering assistance as and when necessary. If you are not happy doing this and you feel that the process of finding the new language should offer more student autonomy, you could have 'time-out' after the practice stage for students to use dictionaries to look up what they need.

As mentioned in the role of the teacher section, feeding-in the language students need is fundamental. By doing so, they will learn new vocabulary and structure in a natural and memorable environment. It is a chance to use real and natural language.

\section{Error Correction}

There are many ways to correct mistakes when using role-play. It is rarely appropriate for the teacher to jump in and correct every mistake. This could be incredibly demotivating! Some students do like to be corrected straight after a role-play activity, while the language is still fresh in their minds. Sentences with errors can be written on the board for the group to correct together. Some ways to correct are self-correction, peer correction, making a note of common mistakes by the teachers and dealing with them in future classes.

\section{Previous studies}

Shen \& Suwanthep (2011) studied the effect of role-play on speaking performance and attitude by the implementation of e-learning on the New Horizon College English (NHCE) e-learning site. In the 18-week research study, all of the instructions, assistance, answers, and feedback served as scaffoldings which allowed students to pose questions and engage in interaction. Results showed that the e-learning constructive role plays had positive effects on improving students"e speaking in terms of language quality and language production, and students express positive opinions towards the implementation of e-learning constructive role plays.

Nouralian et al. (2013) studied the effect of role-play on speaking ability of 100 learners of English at (ILI) Iran language institute in Iran. Then, 40 were selected randomly into two groups: control and experimental. The treatment procedure took 10 sessions. Finally, at the end of the course both groups sat for the post test of speaking ability. The study showed that learner's speaking ability improved more when they were provided with role-plays. 


\section{Participants}

Most students in my class were from the Vocational College of Kiengiang, and some were white collar shirt workers from other organizations in Kiengiang, a province in Melkong Delta in the South of Vietnam where Cantho is the center. Thirty two participated in the research but only twenty four were selected finally and almost all of them were in their 30s and 40s, and five were about 20s and three were about 50s. They followed this degree to get 450 of TOEIC scores or B2 of Vietnamese ranks according to the present demand of the Vietnamese government. They also needed English in higher competence because they have got some training courses for their majors taught and communicated in English in some countries in South East Asian. In the future, the higher demand of English for their work will be the ability to teach their majors in English. The rector informed that he would fire those who could not meet the new criteria of the college in the coming years. Some wanted to follow higher education in English speaking countries as well. They had a short course of English to review for the TOEIC but they thought that it did not work well. To them by studying the second degree of English can ensure that they really get real English competence. As a result, they knew their aim very clearly and all of them try their best. However, their English ability was unequal from elementary level to preintermediate level, but they had not used it for 4 years in average. The common problem was that they were better at reading and grammar than listening, writing and speaking because most learned by grammar translation method in the past.

\section{Sequence of Actions}

Ten topics of role-plays were applied during ten sessions. Before the role-plays, I taught them the lessons in the course books, Tactics for Listening-Basic Pack A \& B and Listening Advantage $1 \& 2$. The first part is the vocabulary in the book, then I give them some more and they ask me some they need for their cases. The meaning, pronunciation, part of speech, usage, and some examples in sentences were taught carefully. Then, some basic structures were introduced to help them speak out in this topic. After they listen some exercises in the books, they were noticed with some more typical language focus to create a good conversation. Next, a model conversation in a paper handout or in the course-book was played first, then they repeated it, then took the roles and practiced it. I had to divide the class to make pairs and groups perfectly. Then, I went around to help them if they needed more such as vocabulary, grammar, etc. A presentation of the model conversation was done afterwards with some comments by me. They were asked to repeat some wrong words, too. Then, a video clip about a model conversation was also played for them to watch with some small tasks such as answering some questions, true or false, or multiple choices, especially notice some functional language focuses by the natives.

The final part was the production role-play. There were two types: first, pairs or small groups; second, the whole class. First, in pairs or small groups, after all procedures above, I wrote the topics of the role-play on the board. They were asked to analyze the topic such as the imaginary person, the imaginary situation, the content, tenses, vocabulary, functional language focuses, etc. With some prompts, they worked in pairs or groups first, then, some pairs or groups presented their performance in front of the class. The comments by the whole class and the teacher were always carried out. The following topics for the type of pair and small group work were:

1. Substitute some information in the model conversation in a paper handout for your real information. (See appendix 2)

2. You are the rector of the Kiengiang Vocational College. There is a new teacher, Mary. Introduce this new teacher to an old teacher and vice versa for them to make friends. (See appendix 1)

3. Work in groups of 4 people. One is a witness who saw a robber in a robbery last week. Describe him for the police. The others guess who the robber is. (See appendix 3)

4. Tomorrow will be a holiday, so you and your close friend will have a day off. Give some suggestions for activities for tomorrow. (See appendix 4)

5. Your friend tells you some thoughts about life in general. Agree or disagree with him

6. A friend is having a health problem. Ask him and give him some advices.

7. You have just had a new friend. Ask him about his house. (See appendix 5)

The topic 'Substitute some information in the model conversation in a paper handout for your real information' was performed every session, so there were ten in total during the research.

The second type of the role-plays was performed in the whole class. They were:

1. The teacher is a Korean pop singer. Interview her about anything.

2. Make a survey about vacation habits in our class. (See appendix 6)

With the topic, 'Asking a Korean pop singer', each student was encouraged to make a question. About half of them tried one. In the survey, all of them had to move around to ask anyone to find the people who had one of five traveling habits on the list. 
The final role-play is 'Make a video clip or an audio file about a conversation of an office worker and a person in your school. This person wants to study a course, so he asks the office worker about the name of the management board, the number of the teachers, the names of the majors, the time of classes, the fee. The office worker asks this person some personal information such as the name, the hometown, the address, the telephone number, the email, the hobbies, favorite majors'. This is an activity after class to help them practice more, especially those that were absent in the lessons about personal information.

\section{Results And Analysis}

With the result of the questionnaire (See appendix 7), the most favorite reason was 'interesting' with the highest mean score at 13.4 ( $\max 20)$, then 'suitable topics' of 6.3, and the third choice was 'easy enough' of 5.6. The others reasons were not remarkable with very low scores. These scores will be clearer with the daily observation and interviews below.

Table 1: Mean of five reasons of participating in ten role-play activities

\begin{tabular}{|l|l|l|c|c|c|}
\hline Reasons & $\begin{array}{l}\text { Suitable } \\
\text { Topics }\end{array}$ & Interesting & Easy Enough & Free of Anxiety & $\begin{array}{l}\text { Easy } \\
\text { and Grammar }\end{array}$ \\
\hline Mean & $6.3(\max 20)$ & $13.4(\max 20)$ & $5.6(\max 20)$ & $3.6(\max 20)$ & $2.4(\max 20)$ \\
\hline Std.deviation & 2.5 & 3.4 & 2.1 & 2.3 & 0.5 \\
\hline
\end{tabular}

According to the observation every session, I saw that all of the ten role-plays' topics were very effective in attracting the students speaking English. Almost all students took part in the role-plays enthusiastically. They asked me immediately when they need my support. In fact, they were not shy at all. They were excited with the information they got from communication. For example, in "Agree or disagree with some life thoughts", one man said, 'I like hot girls.' Another man said, 'Me too.' And the whole class laughed loudly. A 26 year old lady, a 40 year old lady and 38 year old man said, 'Thanks to ten speaking role-plays, I am more confident and have many chances to speak English. In addition, it is easy to make the video clip or the audio file thanks to popular smart phones.'

Also, with language support such as vocabulary, grammar, conversation tips, except three male students in their 50s, almost all of them could use these to speak out in the role-plays. They sometimes look at their notes, but in general they fulfil the tasks successfully. A 40 year old lady said,

I have not used English for 10 years since I graduated from a master program. I got intermediate level 10 years ago. Now I forget a lot, but I can speak out thanks to the vocabulary and structures the teacher gives me.

A 26 year old lady said,

I have not used English for 2 years except some emails sometimes. I sometimes hesitate to speak because I pronounce English wrongly, and I can't remember the words when speaking. I must read the notes to pick up the words, so it makes me difficult. Although the teacher gives me all vocabulary I need, I am too busy to learn them.

Here a 53 year old man said,

I did not learn how to speak in the past, and I have not used English for about 20 years. Therefore, I can't speak English correctly although the teacher gives me all words and structures I need. Among the ten roleplays, I can read the model conversations in spite of many wrong pronunciation, and I can answer very short answer in some tasks. I can't understand the whole class activity such as 'describing the robber'. However, the class is exciting, and I prefer watching than speaking.

With the answer of the man above, it was true that there were always about three men who usually tried to write down some sentences before they talked while the others were talking noisily. On the first day, I didn't understood why the monitor did not talk with an elderly man next to him, he talked to a lady behind him instead. Because this elderly man had no one to talk to, I came to him and practiced the model conversation with him. Since then, I always tried to group the class before the practice so that no one was left behind. However, it didn't work sometimes because of no ability to speak of about these three men. As a result, I was the frequent partner of these men because I could simplify the questions and advised them to answer shortly in one or two words only.

With a clear aim of learning English from the beginning, all of the students had great motivation in speaking English in class as well as after class with a role-play of a video clip or an audio file. Although many were absent on the first day because they had to examine an English exam in their school, fifteen of twenty four students handed me the video clip or the audio clip in the second week. Then, the rest who were busy still sent me the tasks in the third week. Even a mother of two month baby tried to make an audio file for me. They were very proud of their products.

Listening ability was another barrier for them in joining big group or the whole class role-play. In the 
whole class speaking, many of them seemed not to understand what others said. Consequently, they didn't joined in the role-play. A 26 year old lady complained, 'The most difficult role-play is the one by the whole class because I can't get all the information by many people. At first, it is difficult to follow, but later it is better.' A 40 year old lady shared, 'I can't catch up some friends in the whole class activity -describing a robber. I catch up 50\%, but finally I can find out the robber!' In fact, wrong pronunciation of some students in the whole class also caused difficulties in understanding. However, they were more relaxed with the teacher's answer in the task 'Interview the teacher, a Korean pop singer'.

The time of the role-plays made them comfortable. The alternation of language input, listening, and speaking led to effective speaking. A 53 year old lady said that the time was not exhausting for me. She added that although this class was on the weekend, I found out that learning time passed quickly and I felt interested in learning the lesson.

However, the traditional Vietnamese culture of passive learning made almost all reluctant to join in the survey about 'travel habits' actively. They didn't move around. They turned left, turned right, and turned behind only. Only about three men talked to another person of the opposite rows, but females didn't. In fact, the chair arrangement in many long rows without letting interaction didn't create chances for them to interact as well. In short, they were not too passive to do anything, but they tried their best around them. At that time I went around and said, 'Please ask me the questions you haven't got the answers.' Thanks to this, the students near me could finish their work.

\section{Conclusion}

Based on the findings of this research and also from the data analysis, I can conclude that ten role-play can enhance the working students in their 20s-50s to speak English significantly. Although it is difficult for the 50s, they can fulfil their talk in a basic and short answers with the help of the teacher. The role-plays in pairs and small groups help the weak students than the big group but the tasks of big group are more fun. Therefore, I suggest that role-plays should be used in this kind of students. Also, after I failed to persuade a female student to ask a male student nearby to get the information, I was told that they were a couple but they were separated. Therefore, the reasons of not speaking were very important because we can find the effective solution for each of them.

There is a suggestion based on the conclusion above: In the future, the experiment research should be conducted about the speaking performance to know exactly how well they can achieve thanks to role-play.

\section{References}

[1] Bachman, L., \& Palmer, A. S. (1996). Language Testing in Practice. Oxford: Oxford University Press.

[2] Brown, G., \& Yule, G. (1995). Teaching the spoken language. Cambridge: Cambridge University Press.

[3] Canale, M., \& Swain, M. (1980). Theoretical Bases of Communicative Approaches to Second Language Teaching and Testing. Applied Linguistics, 1, 1-47.

[4] Crookall, D., \& Oxford, R. L. (1990b). The island game. In D. Crookall \& R. L. Oxford (Eds.), Simulation, gaming, and language learning (pp. 251-259). New York: Newbury House.

[5] Doff, A. (1998). Teach English: A training Course for Teacher. Cambridge University Press

[6] Ely, C. M. (1986). An analysis of discomfort, risktaking, sociability, and motivation in the L2 classroom. Language Learning, 36, 125 .

[7] Harmer, J. (1991). The Practice of English Language Teaching. The 3th Edition. London: Longman Press.

[8] Horwitz, E. K. (2001). Language anxiety and achievement. Annual Review of Applied Linguistics, 21, 112-126.

[9] Krashen, S. D. (1982). Principles and Practice in Second Language Acquisition. New York: Pergamon Press.

[10] Ladousse, G. P. (2004) Role Play. Oxford: Oxford University Press.

[11] McArthur, T. (1983). A Foundation Course for Language Teachers. Cambridge: Cambridge University Press.

[12] Nation, I.S.P. (1997). The combining arrangement: Some techniques. Modern Language Journal 61(3), 89-94.

[13] Nation, I.S.P. (1997). L1 and L2 use in the classroom: a systematic approach. TESL Reporter $30(2), 19-27$

[14] Nunan, D. (1999). Second Language Teaching \& Learning. Heinle \& Heinle Publishers: An International Thompson Publishing Company, Boston, Massachusetts 02116 USA.

[15] Nouralian et al (2013). The impact of psychodrama (role-play) on Iranian intermediate EFL learner's speaking ability. Indian Journal of Fundamental and Applied Life Sciences 3 (3), 675-682. http://www.cibtech.org/jls.htm

[16] Rajkumar (2012). Innovative Method of Role Play for Developing English Language Teaching and Learning. International journal of Scientific Research, 1(2), 2277 - 8179. http://www.worldwidejournals.com/ijsr/file.php?val=July_2012_1341307684_ d6bd4_File\%2029.pdf

[17] Rivers, W. (1968). Teaching Foreign Language Skills. Chicago: University of Chicago Press.

[18] Role play (2016). Retrieved from http://www.teachingenglish.org.uk/article/role-play

[19] Shen, L., \& Suwanthep, J. (2011). E-learning constructive role plays for EFL learners in China's tertiary education. Asian EFL Journal. Professional Teaching Articles. 49, 1738-1460. The Asian EFL Journal Press. http://www.asian-efl-journal.com.

[20] Snow, D. (2007). A troubleshooter's guide to the Classroom. From language learner to language teacher. (pp. 219-230). TESOL International Association http://www.tesol.org/BookLanding?productID=387\#sthash.U8xMyDM1.dpuf and http://www.tesol.org/docs/books/bk_FromLangLearnToTeacher_387

[21] Teaching speaking skills 2 - overcoming classroom problems (2015) Retrieved from http://www.teachingenglish.org.uk/article/teaching-speaking-skills-2-overcoming-classroom-problems

[22] Ur, P. (1996). A course in Language Teaching. Practice and Theory. Cambridge: Cambridge University Press. 


\section{Appendix 1}

\section{APPENDICES}

\section{Introduction}

You are the rector of the Kiengiang Vocational College. There is a new teacher, Mary. Introduce this new teacher to an old teacher and vice versa for them to make friends.

Sample conversation:

Tom: May. This is my friend, Ben.

Ben, this is my sister, May.

May: Hi. Nice to meet you, Ben.

Ben: Hello. Glad to see you, May.

\section{Appendix 2}

Sample Model Conversation for Substituting the Students' Real Information.

Ted: Everything looks good. What are you going to have, Julie?

Julie: I think I'll have the spaghetti and a salad. How about you? What are you having?

Ted: Spaghetti sounds good, but I feel like a steak. I guess we're ready to order. Excuse me?

Waitress: Good evening. Have you decided yet?

Julie: Yes. I'll have the spaghetti and a salad.

Waitress: And what kind of dressing would you like on your salad?

Julie: I'd like oil and vinegar.

Waitress: Ok. And what would you like, sir?

Ted: I'd like a steak, medium-rare, please.

Waitress: Would you like soup or salad with that?

Ted: What kind of soup do you have tonight?

Waitress: Cream of mushroom and clam chowder.

Ted: Clam chowder,please. And I'll have a baked potato and carrots.

Waitress: I'll be right back with your soup and salad.

Julie: Thank you.

\section{Appendix 3}

Describing a Robber

Work in groups of 4 people. One is a witness who saw a robber in a robbery last week. Describe him for the police. The others guess who the robber is.

- age

- gender

- height

- weight

- hair length

- hair style

- hair color

- eye color

- skin color

- clothes

\section{Appendix 4}

Suggesting activities

Tomorrow will be a holiday, so you and your close friend will have a day off. Give some suggestions for activities for tomorrow.

Some structures:

Let's...go sailing.

Do you want to...eat in a restaurant?

Why don't we.... play soccer?

\section{Appendix 5}

Asking about your new friend's house

You have just had a new friend. Ask him about his house.

Some prompts for making questions:

1. Where/you/live?

2. How many rooms/there/your/house? 
3. What/they?

4. There/a/garden?

5. What/there/the/living room?

6. The toilet/in/bathroom?

7. How/kitchen?

Appendix 6

Making a Survey

Make a survey about vacation habits in our class.

Find someone who:

1. Has been to PhuQuoc island already.

2. Likes mountainous places.

3. Never bargains when shopping.

4. Always takes adventurous games when travel.

5. Has had a disappointing vacation

Appendix 7: Questionnaire about the ten Role Plays

Did you join the activities? Circle all reasons for your joining or your not joining.

1. You are the rector of the Kiengiang Vocational College. There is a new teacher, Mary. Introduce this new teacher to an old teacher and vice versa for them to make friends.

Joined. Why?
a. Suitable topic
b. interesting
c. easy enough
d. Free of anxiety
e. Enough vocabulary and grammar
Not joined. Why?
a. unsuitable topic
b. boring
c. difficult
d. anxiety
e. lack of vocabulary and grammar

2. The role plays based on the model conversations in handouts

Joined. Why?
a. Suitable topic
b. interesting
e. Enough vocabulary and grammar
c. easy enough
d. Free of anxiety
Not joined. Why?
a. unsuitable topic
b. boring
c. difficult
d. anxiety
e. lack of vocabulary and grammar

3. Work in groups of 4 people. One is a witness who saw a robber in a robbery last week. Describe him for the police. The others guess who the robber is.

Joined. Why?
a. Suitable topic
b. interesting
e. Enough vocabulary and grammar
c. easy enough
d. Free of anxiety
Not joined. Why?
a. unsuitable topic
b. boring
c. difficult
d. anxiety
e. lack of vocabulary and grammar

4. Tomorrow will be a holiday, so you and your close friend will have a day off. Give some suggestions for activities for tomorrow.

Joined. Why?

a.Suitable topic

d. Free of anxiety

b. interesting

e. Enough vocabulary and grammar

c. easy enough

Not joined. Why?

a. unsuitable topic

b. boring

c. difficult

d. anxiety

e. lack of vocabulary and grammar

5. Make a video clip or an audio file about a conversation of an office worker and a person in your school. This 
person wants to study a course, so he asks the office worker about the name of the management board, the number of the teachers, the names of the majors, the time of classes, the fee. The office worker asks this person some personal information such as the name, the hometown, the address, the telephone number, the email, the hobbies, favorite majors'.

Joined. Why?

a. Suitable topic

b. interesting

d. Free of anxiety

e. Enough vocabulary and grammar

c. easy enough

Not joined. Why?

a. unsuitable topic

b. boring

e. lack of vocabulary and grammar

c. difficult

d. anxiety

6. The teacher is a Korean pop singer. Interview her about anything

Joined. Why?

a.Suitable topic

b. interesting

d. Free of anxiety

e. Enough vocabulary and grammar

c. easy enough

Not joined. Why?

a. unsuitable topic

b. boring

e. lack of vocabulary and grammar

c. difficult

d. anxiety

7. Your friend tells you some thoughts about life in general. Agree or disagree with him Joined. Why?

a.Suitable topic

d. Free of anxiety

b. interesting

e. Enough vocabulary and grammar

c. easy enough

Not joined. Why?

a. unsuitable topic

b. boring

e. lack of vocabulary and grammar

c. difficult

d. anxiety

8. Make a survey about vacation habits in our class.

Joined. Why?

a.Suitable topic

d. Free of anxiety

b. interesting

e. Enough vocabulary and grammar

c. easy enough

Not joined. Why?

a. unsuitable topic

b. boring

e. lack of vocabulary and grammar

c. difficult

d. anxiety

9. A friend is having a health problem. Ask him and give him some advices.

Joined. Why?

a. Suitable topic

b. interesting

e. Enough vocabulary and grammar

c. easy enough

d. Free of anxiety

Not joined. Why?

a. unsuitable topic

b. boring

e. lack of vocabulary and grammar

c. difficult

d. anxiety

10. You have just had new friend. Ask him about his house

Joined. Why?

a.Suitable topic

d. Free of anxiety

b. interesting

e. Enough vocabulary and grammar

c. easy enough

Not joined. Why?

a. unsuitable topic

b. boring

e. lack of vocabulary and grammar

c. difficult 